\title{
Post-translational enzyme modification by the phosphopantetheinyl transferase is required for lysine and \\ 5 penicillin biosynthesis but not for roquefortine or fatty acid formation in Penicillium chrysogenum
}

10 Carlos García-Estrada*, Ricardo V. Ullán*, Tania Velasco-Conde*, Ramiro P. Godio*, Fernando Teijeira ${ }^{\dagger}$ Inmaculada Vaca*, Raúl Feltrer*, Katarina Kosalková*, Elba Mauriz*, Juan F. Martín*,†

$15 *$ ) Instituto de Biotecnología de León (INBIOTEC). Parque Científico de León, Av. Real, 1, 24006, León, Spain.

$\dagger$ ) Área de Microbiología, Departamento de Biología Molecular, Facultad de CC. Biológicas y Ambientales, Universidad de León, Campus de Vegazana s/n. 24071, León, Spain.

20

25

Corresponding author: Dr. Juan Francisco Martín. Área de Microbiología, Departamento de Biología Molecular, Facultad de CC. Biológicas y Ambientales, Universidad de León, Campus de Vegazana s/n. 24071, León, Spain. Phone: +34 987 291505; Fax: +34 987 291506. E-mail: jf.martin@unileon.es

SHORT TITLE: Role of the stand-alone PPTase of $P$. chrysogenum. 


\section{SYNOPSIS}

Nonribosomal peptide synthetases (NRPSs) and polyketide synthases (PKSs) require a post-translational phosphopantetheinylation to become active. This reaction is catalysed by the 4'-phosphopantetheinyl transferase (PPTase). The ppt gene of Penicillium chrysogenum, encoding a protein that shares 50\% homology with the stand-alone large PPTases, has been cloned. This gene is present as a single copy in the genome of the wild type and high penicillin producing strains (containing multiple copies of the penicillin gene cluster). Amplification of the ppt gene produced increases in isopenicillin $\mathrm{N}$ and benzylpenicillin biosynthesis. A PPTase defective mutant (Wis5460 PPT ) was obtained. It required lysine and lacked pigment and penicillin production, but it still synthesized normal levels of roquefortine. The biosynthesis of roquefortine does not appear to involve a PPTase-mediated modification of the synthesizing enzymes. The PPT mutant did not require fatty acids, which indicates that activation of the fatty acid synthase occurs by a different PPTase. Complementation of Wis54PPT $^{-}$with the ppt gene, restored lysine biosynthesis, pigmentation and penicillin production, which evidences the wide range of processes controlled by this gene.

Keywords: 4'-phosphopantetheinyl transferase, lysine, beta-lactam antibiotics, posttranslational modification, roquefortine, secondary metabolism

Abbreviations used: ACPS, acyl carrier protein synthase; ACV, $\delta(\mathrm{L}-\alpha$-aminoadipyl)-Lcysteinyl-D-valine; ACVS, $\delta(\alpha$-aminoadipyl)-cysteinyl-valine synthetase; ble, bleomycin and phleomycin resistance gene; CP, complex penicillim production medium; DP, defined production medium; FAS, fatty acid synthase; GATase, glutamine amidotransferase; HPLC, high performance liquid chromatography; IOD, integrated optical density; LB, Luria- Bertani broth medium; NRPS, nonribosomal peptide synthetase; PKS, polyketide synthases; ORF, open reading frame; Pgdh, glutamate dehydrogenase gene promoter; PPTase, 4'-phosphopantetheinyl transferase; RT-PCR, reverse transcription-PCR; Teyc1, cytochrome c1 transcriptional terminator. 


\section{INTRODUCTION}

Penicillium chrysogenum is a filamentous fungus which produces penicillins with an 90 aromatic side chain, like benzylpenicillin or phenoxymethylpenicillin [1]. The pathway for penicillin formation has been largely elucidated [2]. It starts with the non-ribosomal biosynthesis of the tripeptide $\delta$ (L- $\alpha$-aminoadipyl)-L-cysteinyl-D-valine (ACV), synthesized by the large multienzyme $\delta(\alpha$-aminoadipyl)-cysteinyl-valine synthetase (ACVS), a typical non-ribosomal peptide synthetase (NRPS) encoded by the $p c b A B$ 95 gene [3-5]. The last steps include cyclization of the ACV tripeptide to isopenicillin $\mathrm{N}$ (catalyzed by the isopenicillin $\mathrm{N}$ synthase encoded by the $p c b C$ gene) and substitution of the L- $\alpha$-aminoadipyl side chain of isopenicillin $\mathrm{N}$ by aromatic acyl side chains (performed by the isopenicillin $\mathrm{N}$ acyltransferase encoded by the penDE gene) [6, 7]. Previous activation of the aromatic acid by a specific aryl-CoA ligase $[8,9]$ is required.

100 The genes involved in the biosynthesis of $\beta$-lactam antibiotics are arranged in clusters in bacteria as well as in filamentous fungi $[1,10,11]$. In $P$. chrysogenum, the three penicillin biosynthetic genes are clustered together in a DNA region, which is amplified in tandem repeats in high producing strains, together with other ORFs [12, 13, 14].

Besides penicillin, $P$. chrysogenum and other filamentous fungi synthesize different

105 secondary metabolites, such as roquefortine and the characteristic green pigment [15]. Multidomain enzymes such as polyketide synthases (PKSs) and nonribosomal peptide synthetases (NRPSs) are in charge of the biosynthesis of secondary metabolites [16-19]. A common feature to these enzymes is that they require a post-translational modification to become active. The apoprotein form (inactive) becomes active (holo

110 form) after the covalent attachment of the 4'-phosphopantetheine moiety, which derives from coenzyme A [20]. Phosphopantetheine has been found to be present in ACV synthetase and in other peptide synthetases [21]. The binding site of this moiety is a serine, which is conserved in all acyl carrier and peptidyl carrier domains present in fatty acid synthases PKSs and NRPSs, respectively [22]. Phosphopantetheine is added

115 to the apoprotein by an enzyme known as a 4'-phosphopantetheinyl transferase (PPTase) $[20,23]$. In the case of the ACVS, the acyl carrier domain (thiolation) of each of the three modules bears a conserved serine residue that binds a thiol-containing phosphopantetheine co-factor $[21,24]$. This co-factor may in turn, form the thioester with the activated amino acid, recognized by the cognate activation (A) domain of each

120 module.

Activation through phosphopantetheine addition is not only found in enzymes of secondary metabolism. Fungi have a unique pathway for the biosynthesis of lysine via the $\alpha$-aminoadipic acid. The $\alpha$-aminoadipate reductase catalyses the conversion of $\alpha$-aminoadipate into $\alpha$-aminoadipate semialdehyde [25-27]. This enzyme is synthesized

125 as a catalytically inactive form, which is activated after the addition of a phosphopantetheinyl group by the PPTase [26, 28, 29].

PPTases have been classified into three major groups according to their substrate specificity. The first class includes the PPTases of bacterial acyl carrier protein synthases (ACPS-type), which are involved in the fatty acid synthesis [20] and in the

130 activation of bacterial polyketide synthases [30]. The second type includes eukaryotic PPTases that constitute an integral domain of fungal type I fatty acid synthases (FASs) [31]. The third group, the Sfp-type PPTases, are twice the size of the ACPS-type enzymes and show a broader range of specificity. PPTases from this family are often associated with a biosynthetic pathway and are required for secondary metabolism in

135 bacteria [20,32] and for lysine biosynthesis in fungi [33]. 
Some strains of $P$. chrysogenum contain an amplification of the penicillin gene cluster (pen) region [12-14] and produce very large amounts of penicillin, thus requiring a high PPTase activity. This might be limiting for ACVS modification unless there is a gene duplication. Therefore, it was important to identify the gene encoding the PPTase of $P$.

140 chrysogenum to elucidate the role of this protein in primary and secondary metabolism. In this work, we report the isolation and characterization of the gene encoding a standalone large (class III) PPTase of $P$. chrysogenum as well as the generation of overexpressing and lack-of-function mutants. Our results indicate that a single PPTase is involved in a wide spectrum of processes, including penicillin production, 145 pigmentation and lysine biosynthesis, but not in fatty acid or roquefortine formation.

\section{EXPERIMENTAL}

\section{Strains and culture conditions}

150 P. chrysogenum NRRL-1951 (wild type) and Wis54-1255 strains, which contain a single copy of the penicillin gene cluster [12], were used as the parental strains in this work. The $P$. chrysogenum Wis54-1255 pyrG $^{-}$strain (an uridine auxotroph derived from the Wis54-1255 strain) and the high penicillin producing strains AS-P-78 and AS-P-99 were used to study the gene copy number. The lysine auxotroph L2/lys ${ }^{-}$strain, a

155 derivative of the L2 mutant strain [34] disrupted in the lys 1 gene (F. Teves et al., unpublished data) was used as control strain of lysine auxotrophy, respectively. Uridine auxotrophs were grown in presence of $140 \mu \mathrm{g} / \mathrm{ml}$ of uridine. Selection of transformants with plasmids carrying the ble maker was made using $30 \mu \mathrm{g} / \mathrm{ml}$ phleomycin. Lysine auxotrophs were grown in the presence of $255 \mu \mathrm{g} / \mathrm{ml}$ of lysine $(1.75 \mathrm{mM})$. Fungal

160 spores were plated on complex Power medium [35] or Czapek minimal medium (30 g/l sucrose, $2 \mathrm{~g} / 1 \mathrm{NaNO}_{3}, 0.5 \mathrm{~g} / 1 \mathrm{~K}_{2} \mathrm{HPO}_{4}, 0.5 \mathrm{~g} / \mathrm{l} \mathrm{MgSO} 4.7 \mathrm{H}_{2} \mathrm{O}, 0.01 \mathrm{~g} / 1 \mathrm{FeSO}_{4}$ ) and grown for seven days at $28^{\circ} \mathrm{C}$. In some experiments, $2,5 \%(\mathrm{v} / \mathrm{v})$ olive oil and 2,5\% (v/v) corn oil were added to the Czapek minimal medium.

$P$. chrysogenum liquid cultures were initiated by inoculating fresh spores in complex

165 medium CIM (20 g/l corn steep solids, $10 \mathrm{~g} / 1$ yeast extract, $58 \mathrm{mM}$ sucrose, $50 \mathrm{mM}$ calcium carbonate, $\mathrm{pH}$ 5.7) or defined DP medium [35] without phenylacetate. After incubation at $25^{\circ} \mathrm{C}$ for $20 \mathrm{~h}$ in an orbital shaker $(250 \mathrm{rpm})$, aliquots were inoculated in complex penicillim production medium CP (4 g/l potassium phenylacetate, $20 \mathrm{~g} / 1$ pharmamedia, $50 \mathrm{~g} / 1$ lactose, $0.03 \mathrm{M}$ ammonium sulphate, $0.05 \mathrm{M}$ calcium carbonate,

$170 \mathrm{pH}$ 6.6) or defined DP medium with phenylacetate.

Competent cells of Escherichia coli DH5 $\alpha$ strain were used for amplification and isolation of plasmid DNA. They were grown in Luria- Bertani Broth medium (LB) with ampicillin $(100 \mu \mathrm{g} / \mathrm{ml})$.

\section{Transformation of $P$. chrysogenum protoplasts}

$P$. chrysogenum protoplasts were obtained and transformed as previously described $[36,37]$. Selection of transformant clones was achieved by complementation of the uridine auxotrophy or by resistance to phleomycin (final concentration of $30 \mu \mathrm{g} / \mathrm{ml}$ ).

\section{Southern and Northern blotting}

DNA and RNA isolation, Southern and Northern blotting were carried out as described before $[8,13,38]$. For hybridizations different probes were used; i) a 1284-bp ppt gene, ii) a 366-bp fragment located inside the ppt gene (see below), iii) a 524-bp EcoRV fragment, which includes the initial $96 \mathrm{bp}$ from the ppt gene plus $428 \mathrm{bp}$ of the 5' 185 region, iv) a 429-bp fragment located inside the third exon of the penDE gene (from 
nucleotide 727 to 1155$)$, v) a fragment including the last 1209-bp of the $p c b A B$ gene and vi) $\beta$-actin gene. The signal provided by the Northern blotting was quantified by densitometry using the "Gel-Pro Analizer" software (Media Cybernetics). The transcript levels were determined comparing the intensity of the ppt mRNA signal to the $\beta$-actin mRNA signal (IOD/IOD $\beta$-actin).

\section{Cloning of the ppt gene}

In order to generate a DNA probe for the isolation of the $P$. chrysogenum ppt gene, PCR was carried out using genomic DNA as template. Two oligonucleotides were designed

195 based upon two conserved amino acid sequences present in the NpgA/CfwA protein (PPTase) of $A$. fumigatus and A. nidulans. A sense oligonucleotide, encoding the conserved motif FNVSHQ, was used as forward primer (Fppt): 5 -ttcaacgtcagccaccaa$3^{\prime}$. As reverse primer, an oligonucleotide encoding the conserved motif WALKEA, was used (Rppt): $5^{\prime}$-cgectctttgagcgecca-3'. Thirty cycles of 1 min denaturation at $94^{\circ} \mathrm{C}, 1$

200 min annealing at $55{ }^{\circ} \mathrm{C}$ and 1 min extension at $72^{\circ} \mathrm{C}$, gave rise to the amplification of a 366-bp band. This band was used as probe to screen a $P$. chrysogenum NRRL-1951 genomic library [12] constructed in the vector $\lambda$ GEM-12 (Promega, Madison, WI, USA). One positive phage was isolated after three consecutive rounds of hybridisation. DNA was isolated from this clone and digested with different restriction enzymes, 205 electrophoresed on $0.7 \%$ agarose gels, transferred by Southern blotting and probed with the 366-bp DNA fragment. Positive bands were sequenced and analysed using the blast algorithms available at http://www.ncbi.nlm.nih.gov/BLAST/.

\section{Intron analysis}

210 Identification of introns was performed by RT-PCR using the "OneStep RT-PCR Kit" (Qiagen, Hilden, Germany) following the manufacturer's instructions. Total RNA was extracted from mycelia grown for $48 \mathrm{~h}$ in CP using the "RNeasy Mini Kit" columns (Qiagen), following the manufacturer's instructions. RNA was treated with RQ1 RNasefree DNase (Promega Corporation) following the manufacturer's instructions. 215 Oligonucleotides ppt1; 5'-atggtagaccccagtgtgtc-3' and ppt2; 5'-ttaaaagcttggtaaatccc-3' were used for this purpose. They were designed to amplify the whole $p p t$ gene. The presence of introns was confirmed by sequencing.

\section{Plasmid constructions}

220 Plasmid p43gdh-ppt was constructed to overexpress the ppt gene in P. chrysogenum as follows: The ppt gene was amplified using primers pptamplF; 5'tcacaatgccatggtagaccccagtgtg-3' and pptamplR; 5'-cagcaagaaggcctttaaaagcttggtaaatc-3' and was cloned in the NcoI-StuI sites of pIBRC43 [39] between the A. awamori gdh gene promoter (a very efficient promoter in ascomycetes) and the Saccharomyces

225 cerevisiae cycl transcriptional terminator. Plasmid pKS-3188ppt contains the 3188-bp DNA fragment released after SalI digestion of the positive phage including the ppt gene. This fragment contains the ppt gene and flanking regions and it was inserted in the SalI restriction site of pBluescript KS +. For some experiments the 3188-bp fragment was amplified by PCR using primers $3188 \mathrm{~F}$; 5'-gtcgaccgaagtggtttcggtt-3' and

230 3188R; 5'-gtcgacgcgggattcgatgctc-3'.

Plasmid pBG, containing the $P$. chrysogenum pyrG gene, has been previously described [38]. Plasmid pJL43-RNAi-ppt is a derivative of the pJL43-RNAi (Ullán et al., unpublished data) and was made for the attenuation of the $p p t$ gene. It was constructed as follows: a 1055-bp exon fragment of the ppt gene, spanning positions 145-1199, was 235 amplified by PCR using primers atppt1; 5'-acgttggtccatggtacatggatgtc-3' and atppt2; 
$5^{\prime}$-aatatcgacctcctccatggggagcca-3' and subcloned into the NcoI site of plasmid pJL43RNAi.

\section{Penicillin bioassays and HPLC analysis}

240 The benzylpenicillin secreted to the culture medium by $P$. chrysogenum was quantified by HPLC and bioassay with Micrococcus luteus as test microorganism. Benzylpenicillin and isopenicillin $\mathrm{N}$ analyses by HPLC were carried out as previously described [38].

\section{Roquefortine extraction and HPLC quantification}

245 Roquefortine $\mathrm{C}$ was determined by HPLC. The mycelium from 72-hour cultures in complex penicillim production medium $\mathrm{CP}$, was washed with $\mathrm{NaCl} 0.9 \%$ and extracted in Falcon ${ }^{\mathrm{TM}}$ tubes with $20 \mathrm{~mL}$ of dichloromethane. The extraction mixture was sonicated for 30 minutes and centrifuged at $4500 \mathrm{rpm}$ for ten minutes at $4^{\circ} \mathrm{C}$. The dichloromethane extract was transferred to a clean tube and evaporated to dryness in a

250 rotary Vacuum Concentrator (RotaVapor-210, Buchi, Switzerland). The residues were re-dissolved in $150 \mu \mathrm{L}$ of methanol, centrifuged and stored at $-20^{\circ} \mathrm{C}$. Chromatographic determinations were performed on a Waters HPLC-system (Waters Corporation, Milford, Massachusetts ,USA) consisting of a 996 Photodiode Array Detector, a binary pump, and a Symmetry reversed-phase $C_{18}$ column $(150 \mathrm{~mm}$ x $3.9 \mathrm{~mm}$ ) of particle size

$2555 \mu \mathrm{m}$ (Waters Corporation) at room temperature. The mobile phase consisted of acetonitrile and water containing $0.04 \%$ trifluoroacetic acid with a flow-rate of 0.7 $\mathrm{mL} / \mathrm{min}$. A linear gradient ranging from (70:30) to (20:80) water-acetonitrile was used for 25 minutes. After 5 minutes at $(20: 80)$ the eluent composition was changed to starting conditions. A standard of pure roquefortine $\mathrm{C}$ was kindly provided by $\mathrm{A}$.

260 Fernández (Biomar S.A.; León, Spain). A stock solution of roquefortine $\mathrm{C}$ was prepared in methanol and stored at $-20^{\circ} \mathrm{C}$. Working standards were prepared just before use by serial dilutions of the stock solution in methanol.

\section{RESULTS AND DISCUSSION}

265

\section{Cloning of the ppt gene from a $P$. chrysogenum genomic library}

To clone the ppt gene of $P$. chrysogenum, two primers (Fppt and Rppt) corresponding to conserved internal sequences from PPTases of the phylogenetically related fungi $A$. fumigatus and $A$. nidulans, were designed. They encode the conserved motifs FNVSHQ

270 and WALKEA, respectively, which are present in the NpgA/CfwA protein (PPTase) of A. fumigatus and A. nidulans. A 366-bp band was amplified, sequenced and compared to the NCBI sequences using the BLAST algorithms. Significant similarities of the PCR product with PPTases (NpgA/CfwA) of A. fumigatus, Neosartorya fischeri, A. clavatus or $A$. nidulans, were found. Therefore, the 366-bp fragment was used as probe to isolate

275 the complete $p p t$ gene from a $P$. chrysogenum NRRL-1951 genomic library in the Lambda phage vector [12]. One positive phage was isolated after three consecutive rounds of hybridisation and its DNA was analysed by Southern blotting with a probe containing the 366-bp DNA fragment (see supplementary material S1). One of the positive bands (the 3188-bp band released after the SalI digestion), was subcloned into a

280 SalI-digested pBluescript KS+, thus generating pKS-3188ppt. Sequence of the 3188-bp region was identical to the sequence 4 reported in the patent application $P$. chrysogenum WO 2005/040369 (Accession No. CS086376), and revealed the presence of a 1284-bp ORF in the center of this region. Upstream of it, a 424-bp ORF (incomplete and present in antisense orientation) showed a strong similarity with a glutamine amidotransferase

285 subunit (PdxT) of $A$. terreus (e-value: 4e-49; Positives: 80\%) and with a glutamine 
amidotransferase (GATase_I) involved in pyridoxine biosynthesis of A. fumigatus (evalue: 4e-49; Positives: $81 \%$ ) or $N$. fischeri (e-value: 1e-48; Positives: $81 \%$ ).

In order to detect the presence of introns within the 1284-bp ORF, RT-PCR assays were carried out using primers ppt1 and ppt2. One 48-bp intron was detected spanning 290 nucleotides 28-75 (data not shown). Sequences of the $5^{\prime}$ and $3^{\prime}$ intron splice sites were the consensus "GTGAGT" and "CAG", respectively. This ORF encoded a PTTase (see below) and the gene was named ppt gene (for phosphopantetheinyl transferase).

The predicted protein sequence encoded by the cDNA of the ppt gene, contained 412 amino acids with an estimated molecular mass of $45,8 \mathrm{kDa}$. This protein was $51 \%$

295 homologous (38\% identity, e-value 3e-64) to the NpgA/CfwA protein (PPTase) of $A$. fumigatus , 51\% homologous to the PPTase of $N$. fischeri (38\% identity, e-value 3e-62), $50 \%$ homologous (38\% identity, e-value: $4 \mathrm{e}-59$ ) to the npgA protein (PPTase) of $A$. nidulans, $48 \%$ homologous (33\% identity, e-value 5e-23) to the PPTase of Gibberella zeae, $46 \%$ homologous (33\% identity, e-value 1e-18) to the PPTase of Magnaporthe

300 grisea and $41 \%$ homologous (28\% identity, e-value $8 \mathrm{e}-16)$ to hypothetical protein related to the npgA protein of Neurospora crassa. The protein product encoded by the ppt gene of $P$. chrysogenum closely resembles the stand-alone large size (class III) PPTases from several filamentous fungi and it shared conserved regions such as "LASQLLK", "FNVSHQA", "VGIDV" and

305 "RLFYSIWALKEAYLKMTGDGLLASWIKDLEF", which are present in the PPTases from several filamentous fungi (Fig. 1) and in the PPTases of other organisms, such as Bacillus subtilis, Homo sapiens, Arabidopsis thaliana or Saccharomyces cerevisiae [40]. This class of fungal PPTases includes the PPTase encoded by the A. nidulans npgA gene, which has been shown to be necessary for penicillin [40], lysine [41] and

310 siderophore biosynthesis [42].

The ppt gene is present as a single copy in the genome of wild type and high penicillin producing strains of $P$. chrysogenum

It is well known that many high penicillin-producing strains contain multiple copies of

315 the pen gene cluster [12]. To determine the ppt gene copy number, genomic DNA from the $P$. chrysogenum NRRL-1951 strain was isolated, digested with different restriction enzymes and hybridised with a probe containing the ppt gene. As shown in figure 2 only one band was detected with most of enzymes. Only ApaI ( 6000 bp and $\sim 700 \mathrm{bp})$ and EcoRI ( $\sim 1600$ bp and $\sim 1100$ bp) gave rise to two hybridisation signals because they 320 cut inside the $p p t$ gene. These results indicate that the $p p t$ gene is present as a single copy in the genome of the wild-type strain of $P$. chrysogenum. The same hybridisation pattern was obtained when the genomic DNA of the high penicillin-producing strains $P$. chrysogenum AS-P-78 and AS-P- 99, was digested with the same restriction enzymes (data not shown). These results evidence that only one copy of this gene exists in the

325 genome of the low and high penicillin producing strains, fact that is consistent with the finding that the $p p t$ gene is not located inside the 56.8-kb amplified region containing the pen gene cluster $[13,14]$.

Amplification of the ppt gene in P. chrysogenum Wis54-1255. Overexpression of the

$330 \quad$ ppt gene leads to increased levels of penicillin

Overexpression of the ppt gene was achieved using plasmid p43gdh-ppt. This plasmid was co-transformed together with plasmid $\mathrm{pBG}$ (which contains the pyrG gene as selectable marker) into the $P$. chrysogenum Wis54-1255 $\mathrm{PyrG}^{-}$strain. Transformants were selected by complementation of the uridine auxotrophy. Ectopic integration of the

335 full Pgdh-ppt-Tcycl cassette in four transformants was confirmed by Southern blotting 
(see supplementary material S2). One of these transformants (T11) was randomly selected for further studies. Northern blottings were carried out with RNA extracted at $48 \mathrm{~h}$ and $72 \mathrm{~h}$ from cultures of the Wis54-1255 strain and transformant T11 to confirm the overexpression of the ppt gene. As observed in figure 3A, transformant T11 showed

340 approximately 3 -fold higher steady-state levels of the ppt transcript than the parental strain and therefore, it was named Wis54-PPT+ strain.

HPLC analyses of the penicillin produced in cultures in DP medium indicated that the specific benzylpenicillin production (per mg of dry weight) of the Wis54-PPT+ strain at 72 hours was up to $30 \%$ higher than that of Wis54-1255 at the same time grown under

345 identical culture conditions (Fig. 3B). Isopenicillin N (an intermediate of the penicillin pathway) production was also determined by HPLC in the Wis54-PPT + strain cultured in complex $\mathrm{CP}$ medium without phenylacetic acid (to optimize isopenicillin $\mathrm{N}$ production). Isopenicillin $\mathrm{N}$ levels in the transformant $\mathrm{T} 11$ were two-fold higher than in the Wis54-1255 strain (Fig. 3C). This result indicates that overexpression of the ppt

350 gene leads to an increase in the initial steps of antibiotic production; i.e. ACV formation or cyclization of ACV to isopenicillin N. Since the 4'-phosphopantetheine moiety is present in the ACVS [21] and it is necessary for the activation of this multidomain enzyme, an increase of the ACVS activity as a consequence of the ppt gene overexpression (giving rise to increased levels of the tripeptide ACV and therefore, to

355 higher levels of antibiotic production), is more likely.

Characterization of mutants defective in PPTase activity. The ppt gene is essential for lysine biosynthesis but not for fatty acids formation

Plasmid pJL43RNAi-ppt (see Experimental Procedures) was used to generate loss-of-

360 function mutants in the PPTase. After transformation, selection of transformants was done through phleomycin resistance. Since the A. nidulans PPTase has been reported as essential for lysine biosynthesis [41], those phleomycin resistant transformants that showed reduced growth on minimal medium or lysine auxotrophy, were selected. Only one clone out of 100 was completely auxotroph for lysine and full integration of the

365 PgpdA-ppt-reversePpcbC cassette was confirmed by Southern blotting (see supplementary material S3). This transformant showed a reorganization of the ppt locus. This fact was confirmed by Southern blotting (Fig. 4A), which was carried out using genomic DNA digested with SalI. A 524-bp EcoRV fragment (absent in the PgpdA-pptreverse $\mathrm{P} p c b C$ attenuation cassette, thus giving information only about the internal $p p t$

370 gene) was used as probe. Results evidenced that the 3188-bp SalI fragment, which includes the endogenous ppt gene, had been reorganized as a 2100-bp band. This generates the deletion of the last $\sim 191 \mathrm{bp}$ of the $p p t$ gene giving rise to a disrupted mutant, which was named Wis54-PPT . Lysine auxotrophy of the ppt disrupted mutant was confirmed growing the Wis54-1255 strain, the Wis54-PPT strain, and the lysine

375 auxotroph L2/lys $1^{-}$strain (as control) in Czapek minimal medium supplemented with $1.75 \mathrm{mM}$ lysine (Fig. 4B). As observed in this figure, addition of lysine is completely essential for growth of the Wis54-PPT strain. This indicates that the ppt gene encodes the PPTase in charge of activation of the $\alpha$-aminoadipate reductase, which catalyses the conversion of $\alpha$-aminoadipic acid into $\alpha$-aminoadipate semialdehyde in the fungal

380 lysine biosynthetic pathway [27].

It was also observed that growth was slower in the Wis54-PPT strain than in the rest of strains. Since the A. nidulans PPTase, encoded by the $n p g A$ gene, is essential for siderophore biosynthesis [42], it is likely that the $P$. chrysogenum PPTase is involved in the maintenance of the intracellular pools of iron through siderophore biosynthesis.

385 However, the lack-of-function mutant Wis54-PPT was able to grow in lysine- 
supplemented minimal medium without addition of siderophores. This indicates that although siderophores have been described in P. chrysogenum $[43,44]$, those might not be essential, unlike the NRPS-mediated siderophore biosynthesis in A. nidulans, which has been shown to be completely necessary for growth [45].

390 A limitation in fatty acid biosynthesis could be another explanation to the growth defects observed in the Wis54-PPT ${ }^{-}$strain. To test this, the parental Wis54-1255 strain, the Wis54-PPT mutant, and the L2/lys1- strain were grown on Czapek minimal medium supplemented with 2,5\% (v/v) olive oil plus 2,5\% (v/v) corn oil. Addition of oils to the minimal medium did not restore the growth rate of the Wis54-PPT strain

395 (see suplementary material S4). This indicates that there must be other PPTases different from that encoded by the $p p t$ gene in charge of the activation of FAS in $P$. chrysogenum. In $S$. cerevisiae the subunit $\alpha$ of FAS is capable of self-pantetheinylation [31]. Probably the same mechanism occurs in P. chrysogenum, where a class of PPTase controls lysine biosynthesis and other class, present as an integral domain of fungal type

400 I FASs, controls fatty acids biosynthesis. This may explain the lack of requirement of fatty acids in the Wis54-PPT mutant.

\section{The ppt gene is involved in penicillin and green pigment formation, but it is not required for roquefortine $\mathrm{C}$ biosynthesis}

405 The Wis54-PPT mutant took 10 days to develop conidiophores and spores in Power medium, unlike the Wis54-1255 strain, which sporulated in about 5 days. White cottonlike conidiophores, unlike the characteristic green conidiophores of the Wis54-1255 strain, were formed in this mutant (see supplementary material S5). The conidia remained colourless due to the inability to synthesize the green pigment, apparently a

410 polyketide-derived compound. It has been reported that the A. nidulans wA gene encodes all or part of a PKS involved in the formation of a green pigment present in conidia [46]. The lack of green pigment formation in the ppt knockout mutant indicates that the PPTase encoded by the ppt gene is also involved in PKSs activation, specially in the activation of the PKS wA-encoded ortholog of $P$. chrysogenum.

415 The role of the ppt gene on secondary metabolism was evident when the penicillin production was tested using sporulated agar plugs (Fig. 5). As shown in this figure, penicillin biosynthesis was completely abolished in the Wis54-PPT strain. The same results were obtained úsing filtrates from submerged cultures in complex $\mathrm{CP}$ medium (see supplementary material S5). The lack of antibiotic production was not due to a

420 reorganization of the penicillin biosynthetic cluster in the Wis54-PPT strain, as we confirmed by Southern blotting (see supplementary material S6). Instead, it is likely accounted by the absence of activity of the ACVS, since this NRPS requires phosphopantetheine-mediated activation of the constituent peptidyl carrier domain to catalyse the biosynthesis of the tripeptide ACV [5,21,24,47]. In addition, the 425 isopenicillin $\mathrm{N}$ synthase, which is a nonheme $\mathrm{Fe}^{2+}$-dependent oxygenase [48] may have a reduced activity in the Wis54-PPT mutant, since the availability of iron might become limiting because of a defect in the siderophore biosynthesis.

In addition to $\beta$-lactam antibiotics, $P$. chrysogenum is able to produce other secondary metabolites, such as the alkaloid roquefortine $\mathrm{C}$ [15]. The biosynthesis of this

430 mycotoxin is poorly known; it is believed to be formed by a NRPS (the gene encoding this NRPS has not been cloned yet) that uses dimethylallyltryptophan as one of the precursors [49]. When the roquefortine $C$ biosynthesis was anslysed by HPLC in the Wis54-PPT mutant and in the Wis54-1255 strain, no differences were found between these two strains (see supplementary material S7), which suggests that the biosynthesis 435 of roquefortine may not require post-translational modification by the PTTase. 
Alternatively, the presence of a second PPTase involved in the activation of the NRPS in charge of the biosynthesis of this alkaloid, cannot be excluded.

Complementation of the Wis54-PPT strain with the ppt gene restores lysine 440 biosynthesis, normal growth rate, pigmentation and penicillin production In order to confirm the role of the P. chryosgenum PPTase in lysine biosynthesis and secondary metabolism, the Wis54-PPT strain was complemented with plasmid pKS3188ppt (see Experimental Procedures). Integration of the 3188-bp region, which includes the ppt gene, was confirmed by PCR (Fig. 6A). Transformants were selected 445 by their ability to grow in presence of phleomycin (a characteristic of the Wis54-PPT strain) and lysine prototrophy restoration was confirmed in one of the transformants (randomly selected) (Fig. 6B). The transformant showed a growth rate similar to that of the Wis54-1255 strain. In addition, the green pigmentation of conidiophores and penicillin production were completely restored in the complemented transformant (see supplementary material S8).

All these data, taken together, indicate that the $P$. chrysogenum stand-alone large size (class III) PPTase encoded by the ppt gene is in charge of the post-translational activation of the $\alpha$-aminoadipate reductase, ACVS and the NRPS involved in the green

455 pigment formation, evidencing that this protein is involved in the post-translational control of both primary and secondary metabolism.

\section{ACKNOWLEDGEMENTS}

460 This work was supported by grants of the European Union (Eurofung II) and DSM (Delft, Holland). C. García-Estrada is supported by the Torres Quevedo Program (PTQ04-3-0411). Authors wish to thank B. Martín, J. Merino, A. Casenave and B. Aguado (Instituto de Biotecnología, INBIOTEC) for their excellent technical assistance.
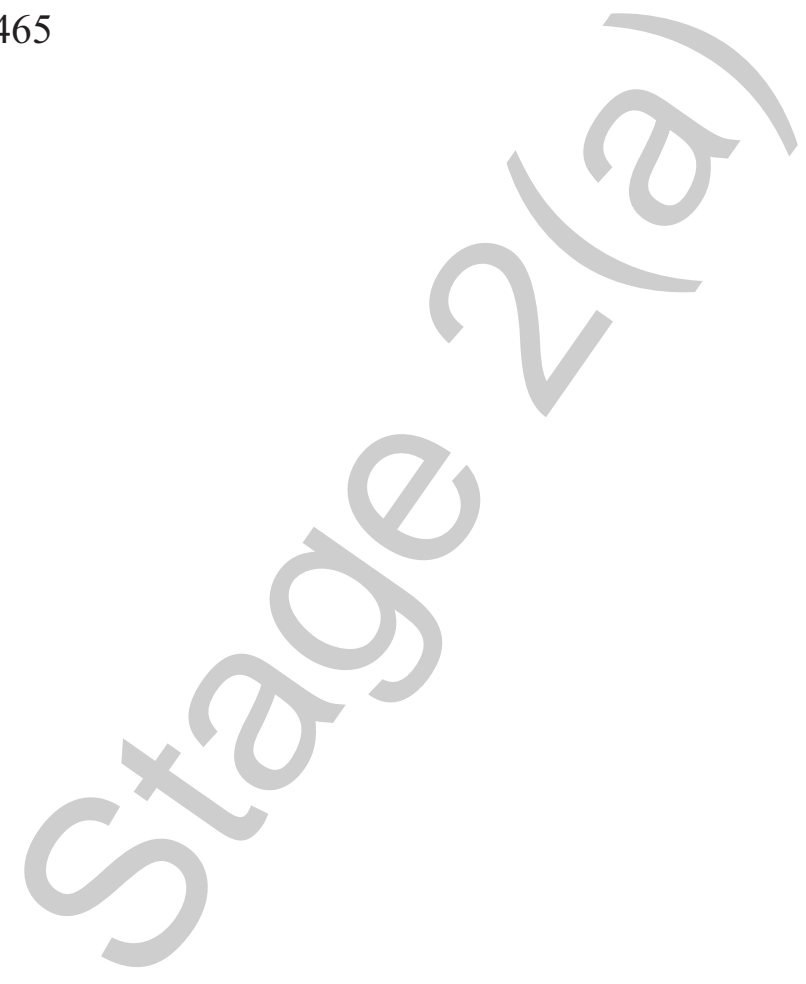


\section{REFERENCES}

1 Aharonowitz, Y., Cohen, G., and Martín, J.F. (1992) Penicillin and cephalosporin biosynthetic genes: structure, regulation, and evolution. Annu. Rev. Microbiol. 46, 461-495

2 Martín, J.F., Gutiérrez, S., Fernández, F.J., Velasco, J., Fierro, F., Marcos, A.T. and Kosalkova, K. (1994) Expression of genes and processing of enzymes for the biosynthesis of penicillins and cephalosporins. Antonie van Leeuwenhoek 65, 227243

4753 Díez, B., Gutiérrez, S., Barredo, J.L., van Solingen, P., van der Voort, Lucia, H.M., and Martín, J.F. (1990) The cluster of penicillin biosynthetic genes. J. Biol. Chem. 265, 16358-16365

4 Byford, M.F., Baldwin, J.E., Shiau, C.Y., and Schofield, C.J. (1997) The 480 mechanisms of ACV synthetase. Chem. Rev. 97, 2631-2650

5 Martín, J.F. (2000) $\alpha$-aminoadipyl-cysteinyl-valine synthetases in $\beta$-lactam producing organisms. From Abraham's discoveries to novel concepts of nonribosomal peptide synthesis. J. Antibiot. 53,1008-1021

6 Álvarez, E., Cantoral, J.M., Barredo, J.L., Díez, B., and Martín, J.F. (1987)

485 Purification to homogeneity and characterization of the acyl-CoA: 6-APA acyltransferase of Penicillium chrysogenum. Antimicrob. Agents Chemother. 31, $1675-1682$

7 Martín, J.F., Ingolia, T.D., and Queener, S.W. (1990) Molecular genetics of penicillin and cephalosporin antibiotic biosynthesis. In Molecular Industrial

490 Mycology (Leong, S.A. and Berka, R. eds.), pp. 149-195, Marcel Dekker, New York

8 Lamas-Maceiras, M., Vaca, I., Rodríguez, E., Casqueiro, J., and Martín, J.F. (2006) Amplification and disruption of the phenylacetyl-CoA ligase gene of Penicillium chrysogenum encoding an aryl-capping enzyme that supplies phenylacetic acid to the isopenicillin N acyltransferase. Biochem. J. 395, 147-155

9 Wang, F.Q., Liu, J., Dai, M., Ren, Z.H., Su, C.Y., and He, J.G. (2007) Molecular cloning and functional identification of a novel phenylacetyl-CoA ligase gene from Penicillium chrysogenum. Biochem. Biophys. Res. Commun. 360, 453-458

10 Martín, J.F. and Liras, P. (1989) Organization and expression of genes involved in 500 the biosynthesis of antibiotics and other secondary metabolites. Annu. Rev. Microbiol. 43, 173-206

11 Martín, J.F. (1998) New aspects of genes and enzymes for beta-lactam antibiotic biosynthesis. Appl. Microbiol. Biotechnol. 50, 1-15.

12 Fierro, F., Barredo, J.L., Díez, B., Gutiérrez, S., Fernández, F.J. and Martín, J.F. 505 (1995) The penicillin gene cluster is amplified in tandem repeats linked by conserved hexanucleotide sequences. Proc. Natl. Acad. Sci. USA. 92, 6200-6204

13 Fierro, F., García-Estrada, C., Castillo, I., Rodríguez, R., Velasco-Conde, T., and Martín, J.F. (2006) Transcriptional and bioinformatic analysis of the $56.8 \mathrm{~kb}$ DNA region amplified in tandem repeats containing the penicillin gene cluster in Penicillium chrysogenum. Fungal Genet. Biol. 43, 618-629 
14 van den Berg, M.A., Westerlaken, I., Leeflang, C., Kerkman, R., and Bovenberg, R.A. (2007) Functional characterization of the penicillin biosynthetic gene cluster of Penicillium chrysogenum Wisconsin54-1255. Fungal Genet. Biol. 44, 830-844

15 Keller, N.P., Turner, G., and Bennett, J.W. (2005) Fungal secondary metabolism from biochemistry to genomics. Nat. Rev. Microbiol. 3, 937-947

16 Von Dohren, H., Keller, U., Vater, J., and Zocher, R. (1997) Multifunctional Peptide Synthetases. Chem. Rev. 97, 2675-2706

17 Marahiel, M.A., Stachelhaus, T., and Mootz, H.D. (1997) Modular Peptide Synthetases Involved in Nonribosomal Peptide Synthesis. Chem. Rev. 97, 2651$520 \quad 2674$

18 Metz, J.G., Roessler, P., Facciotti, D., Levering, C., Dittrich, F., Lassner, M., Valentine, R., Lardizabal, K., Domergue, F., Yamada, A., Yazawa, K., Knauf, V., and Browse, J. (2001) Production of polyunsaturated fatty acids by polyketide synthases in both prokaryotes and eukaryotes. Science 293, 290-293

52519 Cox, R.J. (2007) Polyketides, proteins and genes in fungi: programmed nanomachines begin to reveal their secrets. Org. Biomol. Chem. 5, 2010-2026

20 Lambalot, R.H., Gehring, A.M., Flugel, R.S., Zuber, P., LaCelle, M., Marahiel, M.A., Reid, R., Khosla, C., and Walsh, C.T. (1996) A new enzyme superfamily the phosphopantetheinyl transferases. Chem. Biol. 3, 923-936

53021 Baldwin, J.E., Bird, J.W., Field, R.A., O'Callaghan, N.M., Schofield, C.J., and Willis, A.C. (1991) Isolation and partial purification of ACV synthetase from Cephalosporium acremonium and Streptomyces clavuligerus: evidence for the presence of phosphopantothenate in ACV synthetase. J. Antibiot. 44, 241-248

22 Martín, J.F. and Gutiérrez, S. (1992) Molecular genetics of fungal secondary 535 metabolites. In Applied Molecular of filamentous Fungi. (Kinghorn J.R., and Turner G., eds.), pp. 214-252, Blackie and Son, Ltd., Glasgow

23 Walsh, C.T., Gehring, A.M., Weinreb, P.H., Quadri, L.E., and Flugel, R.S. (1997) Post-translational modification of polyketide and nonribosomal peptide synthases. Curr. Opin. Chem. Biol. 1, 309-315

54024 Kleinkauf, H. and von Döhren, H. (1995) The nonribosomal peptide biosynthetic system- on the origins of structural diversity of peptides, cyclopeptides and related compounds. Antonie van Leeuwenhoek 67, 229-242

25 Bhattacharjee, J.K. (1985) Alpha-Aminoadipate pathway for the biosynthesis of lysine in lower eukaryotes. Crit. Rev. Microbiol. 12, 131-151

54526 Ehmann, D.E., Gehring, A.M., and Walsh, C.T. (1999). Lysine biosynthesis in Saccharomyces cerevisiae: mechanism of alpha-aminoadipate reductase (Lys2) involves posttranslational phosphopantetheinylation by Lys5. Biochemistry 38, 6171-6177.

27 Casqueiro, J., Gutiérrez, S., Bañuelos, O., Fierro, F., Velasco, J. and Martín, J.F. 550 (1998) Characterization of the lys 2 gene of Penicillium chrysogenum encoding $\alpha$ aminoadipic acid reductase. Mol. Gen. Genet. 259, 549-556

28 Garrad, R.C., and Bhattacharjee, J.K. (1992) Lysine biosynthesis in selected pathogenic fungi: characterization of lysine auxotrophs and the cloned LYS1 gene of Candida albicans. J. Bacteriol. 174, 7379-7384 
55529 Guo, S., Evans, S.A., Wilkes, M.B., and Bhattacharjee, J.K. (2001) Novel posttranslational activation of the LYS2-encoded alpha-aminoadipate reductase for biosynthesis of lysine and site-directed mutational analysis of conserved amino acid residues in the activation domain of Candida albicans. J. Bacteriol. 183, 7120-7125 30 Suo, Z., Tseng, C.C., and Walsh C.T. (2001) Purification, priming, and catalytic peptidyl synthetase modules of the HMWP1 subunit of yersiniabactin synthetase. Proc. Natl. Acad. Sci. USA. 98, 99-104

31 Fichtlscherer, F., Wellein, C., Mittag, M., and Schweizer, E. (2000) A novel function of yeast fatty acid synthase. Subunit alpha is capable of selfpantetheinylation. Eur. J. Biochem. 267, 2666-2671

32 Mofid, M.R., Finking, R., and Marahiel, M.A. (2002) Recognition of hybrid peptidyl carrier proteins/acyl carrier proteins in nonribosomal peptide synthetase modules by the 4'-phosphopantetheinyl transferases AcpS and Sfp. J. Biol. Chem. 277, 17023-17031

57033 Mootz, H.D., Schörgendorfer, K., and Marahiel, M.A. (2002) Functional characterization of 4'-phosphopantetheinyl transferase genes of bacterial and fungal origin by complementation of Saccharomyces cerevisiae lys5. FEMS Microbiol. Lett. 213, 51-57

34 Esmahan, C., Álvarez, E., Montenegro, E., and Martín, J.F (1994) Catabolism of lysine in Penicillium chrysogenum leads to formation of $\alpha$-aminoadipic acid, a precursor of penicillin biosynthesis. Appl. Environ. Microbiol. 60, 1705-1710

35 Casqueiro, J., Bañuelos, O., Gutiérrez, S., Hijarrubia, M.J., and Martín, J.F. (1999) Intrachromosomal recombination between direct repeats in Penicillium chrysogenum: gene conversion and deletion events. Mol. Gen. Genet. 261, 994-1000

58036 Cantoral, J.M., Díez, B., Barredo, J.L., Alvarez, E., and Martín, J.F. (1987) High frequency transformation of Penicillium chrysogenum. Bio/Technology 5, 494-497

37 Díez, B., Álvarez, E., Cantoral, J.M., Barredo, J.L., and Martín, J.F. (1987) Isolation and characterization of pyrG mutants of Penicillium chrysogenum by resistance to 5'-fluorotic acid. Curr. Genet. 12, 277-282

58538 García-Estrada, C., Vaca, I., Lamas-Maceiras, M., and Martín, J.F. (2007) In vivo transport of the intermediates of the penicillin biosynthetic pathway in tailored strains of Penicillium chrysogenum. Appl. Microbiol. Biotechnol. 76, 169-82

39 Cardoza, R.E., Moralejo, F.J., Gutiérrez, S., Casqueiro, J., Fierro, F., and Martín, J.F. (1998) Characterization and nitrogen-source regulation at the transcriptional

$590 \quad$ level of the gdhA gene of Aspergillus awamori encoding an NADP-dependent glutamate dehydrogenase. Curr. Genet. 34, 50-59

40 Keszenman-Pereyra, D., Lawrence, S., Twfieg, M.E., Price, J., and Turner, G. (2003) The npgA/ cfwA gene encodes a putative 4'-phosphopantetheinyl transferase which is essential for penicillin biosynthesis in Aspergillus nidulans. Curr. Genet.

$595>\mathbf{4 3}, 186-190$

41 Márquez-Fernández, O., Trigos, A., Ramos-Balderas, J.L., Viniegra-Gonzalez, G., Deising, H.B., and Aguirre, J. (2007) Phosphopantetheinyl transferase CfwA/NpgA is required for Aspergillus nidulans secondary metabolism and asexual development. Eukaryot. Cell 6, 710-720 
60042 Oberegger, H., Eisendle, M., Schrettl, M., Graessle, S., and Haas, H. (2003) 4'phosphopantetheinyl transferase-encoding npgA is essential for siderophore biosynthesis in Aspergillus nidulans. Curr. Genet. 44, 211-215

43 Charlang, G., Ng, B., Horowitz, N.H., and Horowitz, R.M. (1981) Cellular and extracellular siderophores of Aspergillus nidulans and Penicillium chrysogenum.

605 Mol. Cell. Biol. 1, 94-100

44 Charlang, G., Horowitz, R.M., Lowy, P.H., Ng, B., Poling, S.M., and Horowitz, N.H. (1982) Extracellular siderophores of rapidly growing Aspergillus nidulans and Penicillium chrysogenum. J. Bacteriol. 150, 785-787

45 Eisendle, M., Oberegger, H., Zadra, I., and Haas, H. (2003) The siderophore system is essential for viability of Aspergillus nidulans: functional analysis of two genes encoding 1-ornithine $\mathrm{N}$ 5-monooxygenase ( $\operatorname{sid} A$ ) and a non-ribosomal peptide synthetase (sidC). Mol. Microbiol. 49, 359-375

46 Mayorga, M.E., and Timberlake, W.E. (1992) The developmentally regulated Aspergillus nidulans wA gene encodes a polypeptide homologous to polyketide and fatty acid synthases. Mol. Gen. Genet. 235, 205-212

47 Aharonowitz, Y., Bergmeyer, J., Cantoral, J.M., Cohen, G., Demain, A.L., Fink, U., Kinghorn, J., Kleinkauf, H., MacCabe, A., Palissa, H., et al. (1993 ) Delta-(L-alphaaminoadipyl)-L-cysteinyl-D-valine synthetase, the multienzyme integrating the four primary reactions in beta-lactam biosynthesis, as a model peptide synthetase.

620 Biotechnology 11, 807-810

48 Bainbridge, Z.A., Scott, R.I. and Perry, D. (1992) Oxygen utilization by isopenicillin N synthase from Penicillium chrysogenum. J. Chem. Technol. Biotechnol. 55, 233-238

49 Steiner, U., Ahimsa-Müller, M.A., Markert, A., Kucht, S., Gross, J., Kauf, N., Kuzma, M., Zych, M., Lamshöft, M., Furmanowa, M., et al. (2006) Molecular characterization of a seed transmitted clavicipitaceous fungus occurring on dicotyledoneous plants (Convolvulaceae). Planta 224, 533-544

630

635 


\section{FIGURE LEGENDS}

Figure 1. Alignment of the conserved motifs present in the $P$. chrysogenum PPTase 650 to different PPTases from several filamentous fungi.

npgA (PPTase) from A. nidulans (Accession No. AAF12814) (npgAAnidu); PPTase NpgA/CfwA from Aspergillus fumigatus (Accession No. XP_755193) (npgAAfum); protein NpgA related to null pigmentation protein from Neurospora crassa (Accession No. CAE76613) (npgANcras); hypothetical protein MGCH7_ch7g840 from

655 Magnaporthe grisea (Accession No. XP_001522742) (PPTaseMgri) and hypothetical protein FG08779.1 from Gibberella zeae (Accession No. XP_388955) (PPTaseGzea). These proteins were aligned to the $P$. chrysogenum PPTase (PPTasePchr) using the ClustalX program. Note the strong conservation of amino acids 224-254.

660 Figure 2. Southern blot analysis of the ppt gene copy number in P. chrysogenum. DNA from the $P$. chrysogenum NRRL-1951 wild type strain was digested with several restriction enzymes (A: ApaI; B: BamHI; E: EcoRI; H: HindIII; K: KpnI; N: NcoI; P: PstI; S: SacI; Sa: SalI; X: XhoI). The P. chrysogenum ppt gene was used as probe. The $\lambda$-HindIII molecular mass marker is indicated as $\mathrm{M}$.

Figure 3. Amplification of the ppt gene in $P$. chrysogenum.

A) Northern blottings performed with samples taken after $48 \mathrm{~h}$ and $72 \mathrm{~h}$ from cultures of the transformant T11 (PPT+) and the Wis54-1255 strain (Wis54) grown in CP medium. The filter was hybridised to a probe containing a fragment of the ppt gene. As

670 a control of RNA levels loaded in the gel, a probe with the $\beta$-actin gene was used. The steady-state levels of the pptase transcripts of transformant T11 (PPT+) and Wis541255 strain were determined by densitometry. Transformant T11 was referred hereafter as Wis54-PPT+ strain. B) Representative HPLC chromatogram of the filtrates obtained from one of the liquid cultures (72 hours) of the Wis54-PPT+ and Wis54-1255 strains

675 under penicillin production conditions. Three different experiments with duplicate flasks were done. Potassium benzylpenicillin (PenG) was used as control. C) Isopenicillin N specific production of the Wis54-PPT+ and Wis54-1255 strains after 24 $\mathrm{h}, 48 \mathrm{~h}$ and $72 \mathrm{~h}$ of growth in CP medium without the addition of phenylacetic acid. Three different experiments with duplicate flasks were done and isopenicillin $\mathrm{N}$ levels

680 were determined by HPLC. Three determinations were done for each value. Vertical bars indicate the standard deviation.

Figure 4. Disruption of the ppt gene leads to lysine auxotrophy.

A) Southern blotting performed with total DNA digested with SalI and probed with a 685 524-bp EcoRV fragment (grey box), which includes the first 96 bp of the ppt gene plus $428 \mathrm{bp}$ of the $5^{\prime}$ region. Note the size reduction of the 3188 -bp band containing the $p p t$ gene in the Wis54-PPT strain. The $\lambda$-HindIII molecular mass marker is indicated as M. B) Growth of Wis54-1255, the lysine auxotroph L2/lys1- and Wis54-PPT strains in Czapek minimal medium with or without addition of $1.75 \mathrm{mM}$ lysine.

690

Figure 5. Role of the ppt gene in penicillin production.

Bioassay of sporulated agar plugs showing that benzylpenicillin biosynthesis is completely abolished in the Wis54-PPT strain grown on solid medium. The Wis541255 strain was used as control.

695

Figure 6. Complementation of the Wis54-PPT ${ }^{-}$strain with the ppt gene. 
A) Electrophoresis of the PCR product obtained after amplification of the 3188-bp region, which includes the ppt gene. The PCR was carried out using DNA extracted from the complemented (Com), the Wis54-PPT (PPT) and Wis54-1255 (Wis) strains

700 and the primers specified in Experimental Procedures. Note the integrity of the 3188-bp band in the complemented and Wis54-1255 strains and the lack of amplification in the Wis54-PPT ${ }^{-}$strain as a consequence of the ppt gene disruption. The authenticity of this band was confirmed by sequencing the PCR product. B) Growth of one randomlyselected transformant (Comp) obtained after complementation of the Wis54-PPT strain with the 3188-bp ptt region in Czapek minimal medium without lysine addition. The Wis54-1255, Wis54-PPT ${ }^{-}$and L2/lys $1^{-}$strains were included as controls. 

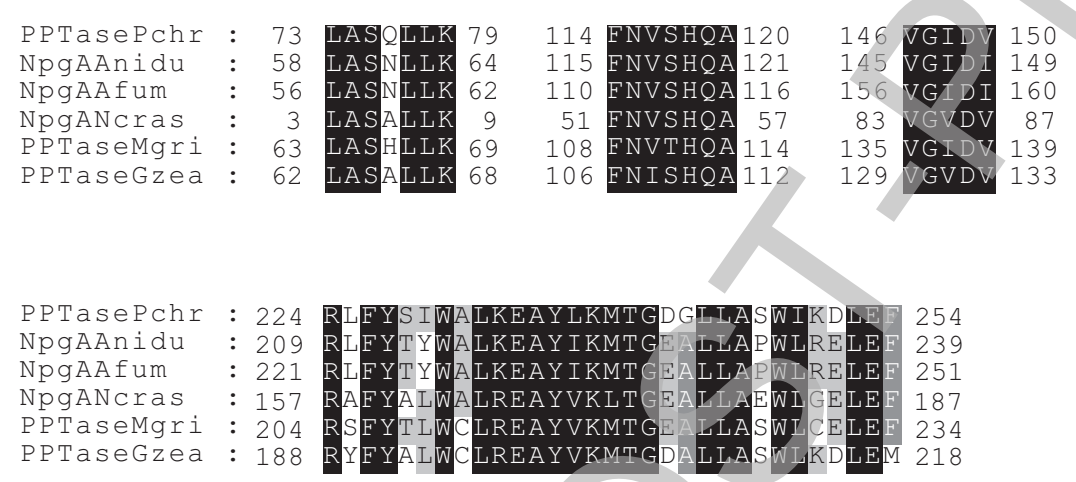

Figure 1. García-Estrada et al.

Licenced copy. Copying is not permitted, except with prior permission and as allowed by law. (C) 2008 The Authors Journal compilation (c) 2008 Biochemical Society 


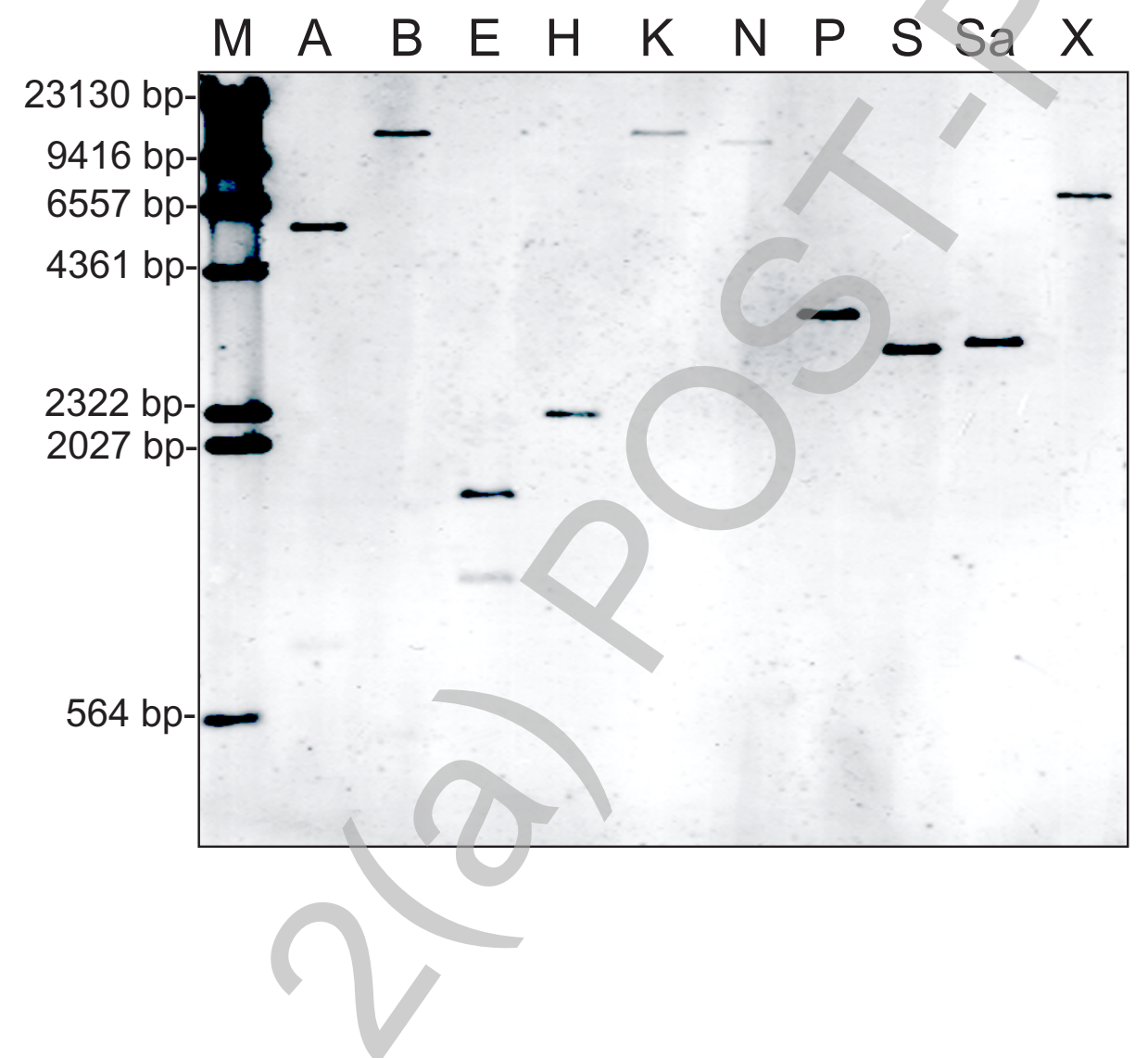

Figure 2. García-Estrada et al. 
Biochemical Journal Immediate Publication. Published on 18 Jun 2008 as manuscript BJ20080369
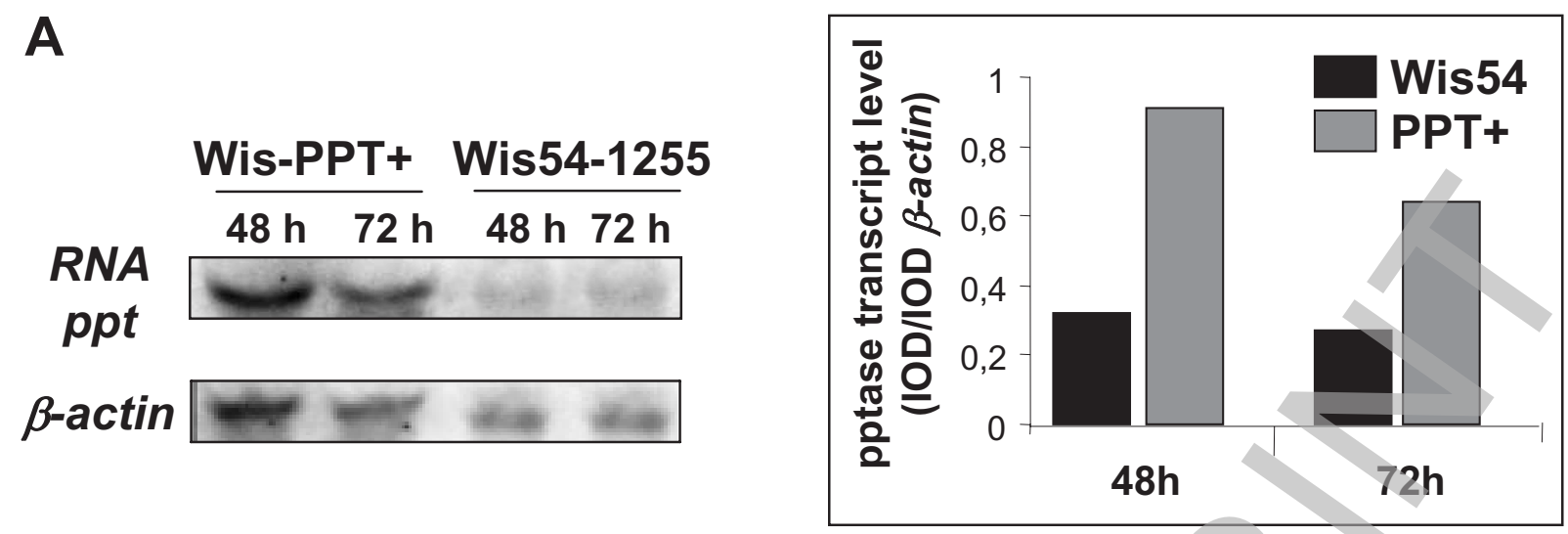

B
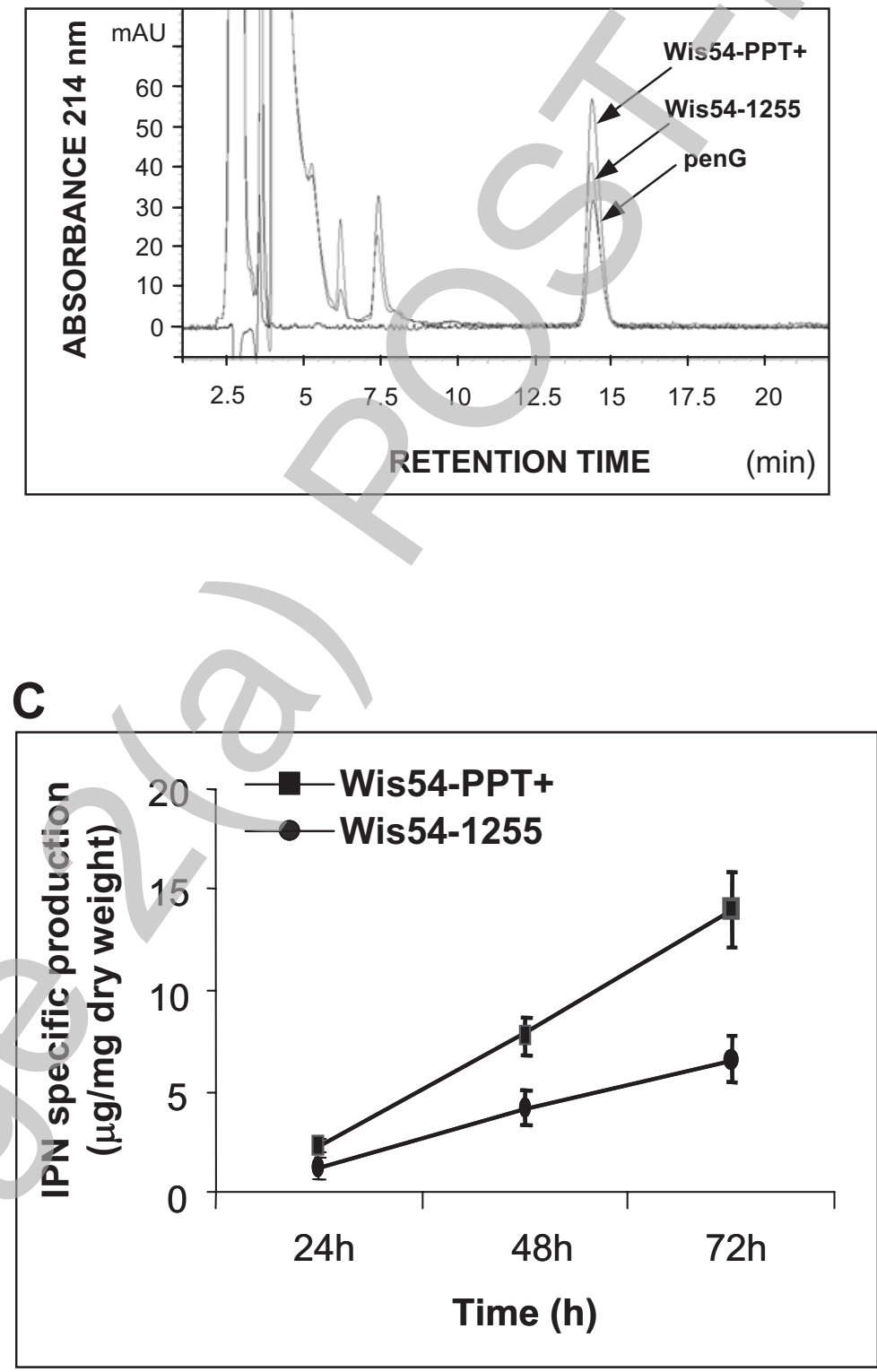

Figure 3. García-Estrada et al.

Licenced copy. Copying is not permitted, except with prior permission and as allowed by law.

(C) 2008 The Authors Journal compilation (C) 2008 Biochemical Society 
Biochemical Journal Immediate Publication. Published on 18 Jun 2008 as manuscript BJ20080369
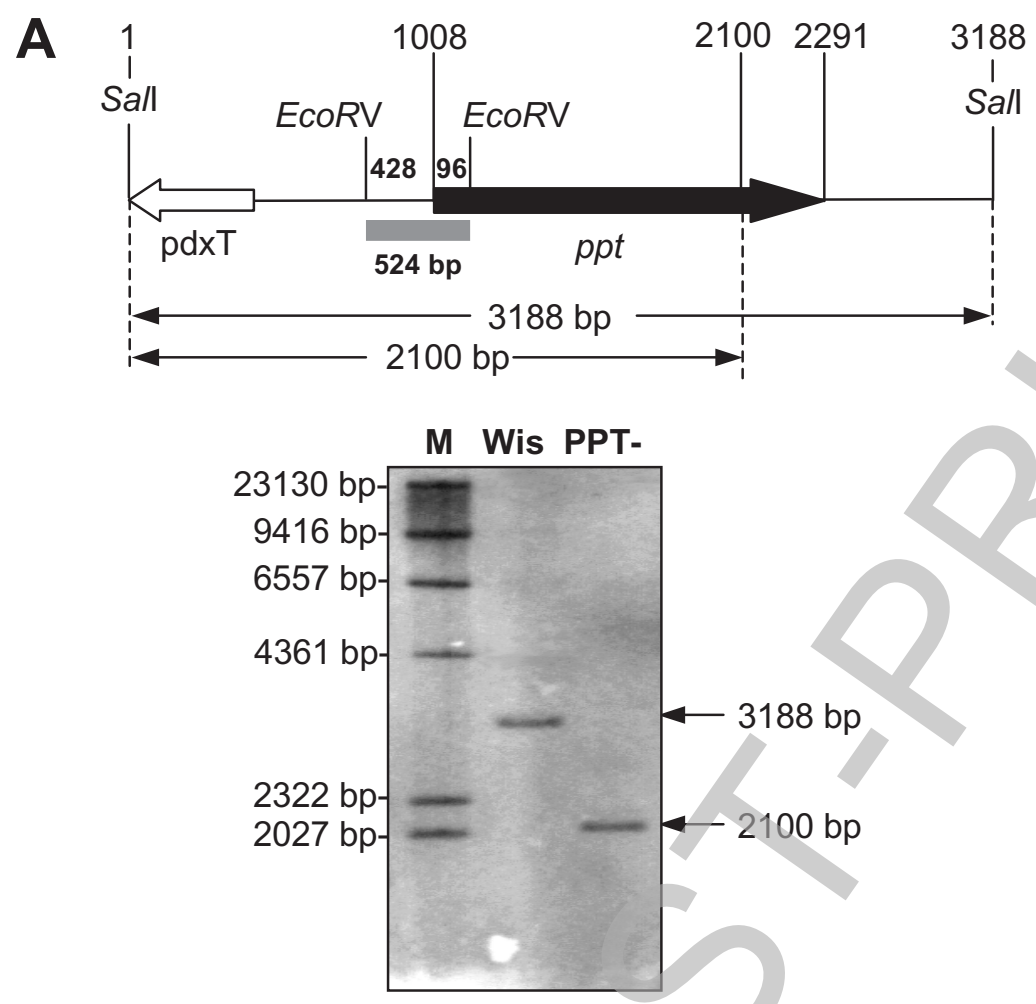

B

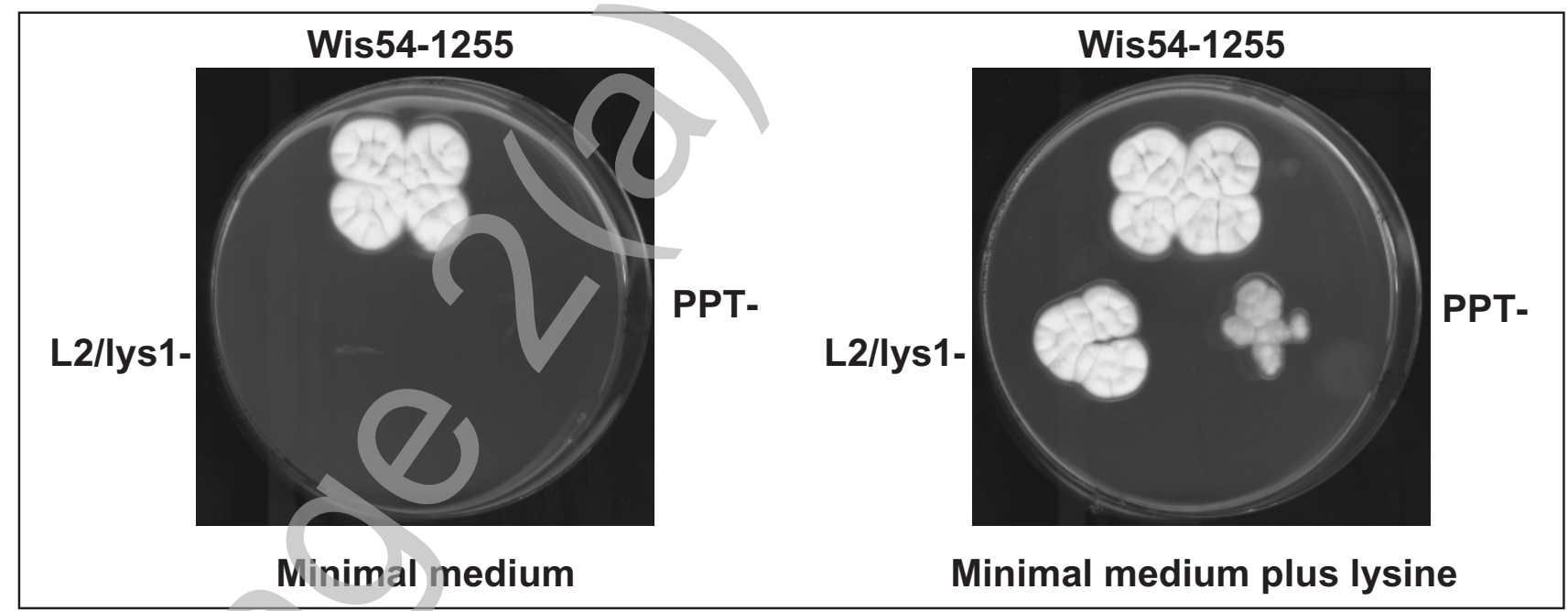

Figure 4. García-Estrada et al.

Licenced copy. Copying is not permitted, except with prior permission and as allowed by law.

(c) 2008 The Authors Journal compilation (c) 2008 Biochemical Society 


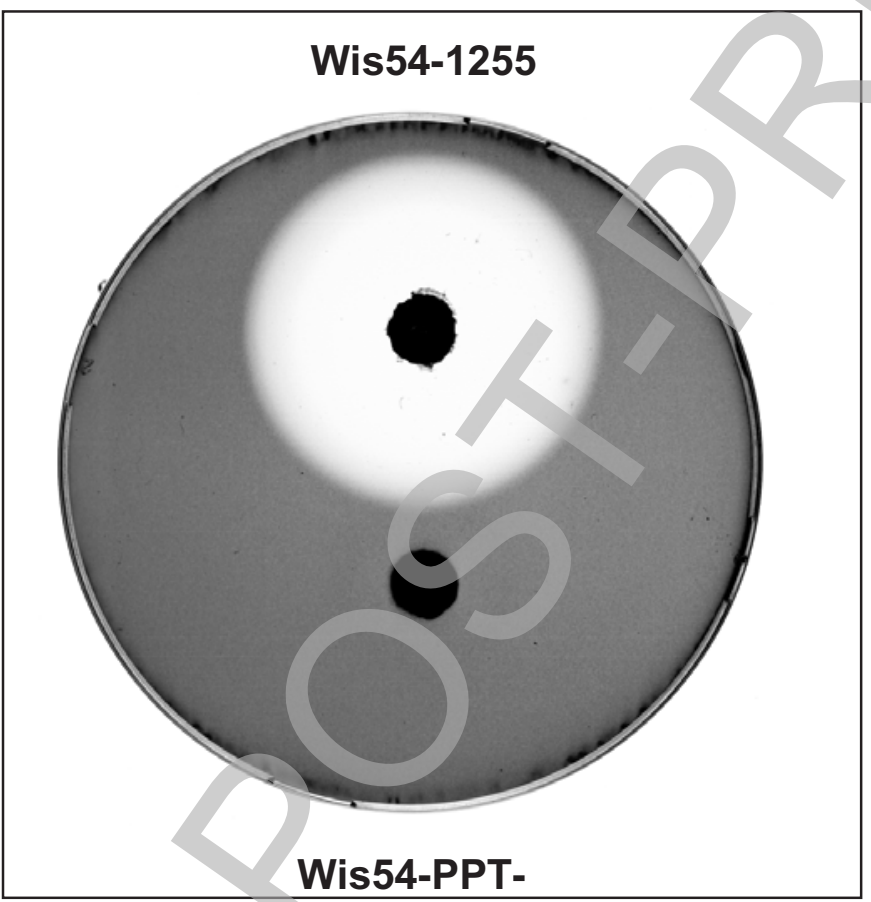

Figure 5. García-Estrada et al.

Licenced copy. Copying is not permitted, except with prior permission and as allowed by law. (C) 2008 The Authors Journal compilation (C) 2008 Biochemical Society 
Biochemical Journal Immediate Publication. Published on 18 Jun 2008 as manuscript BJ20080369

A

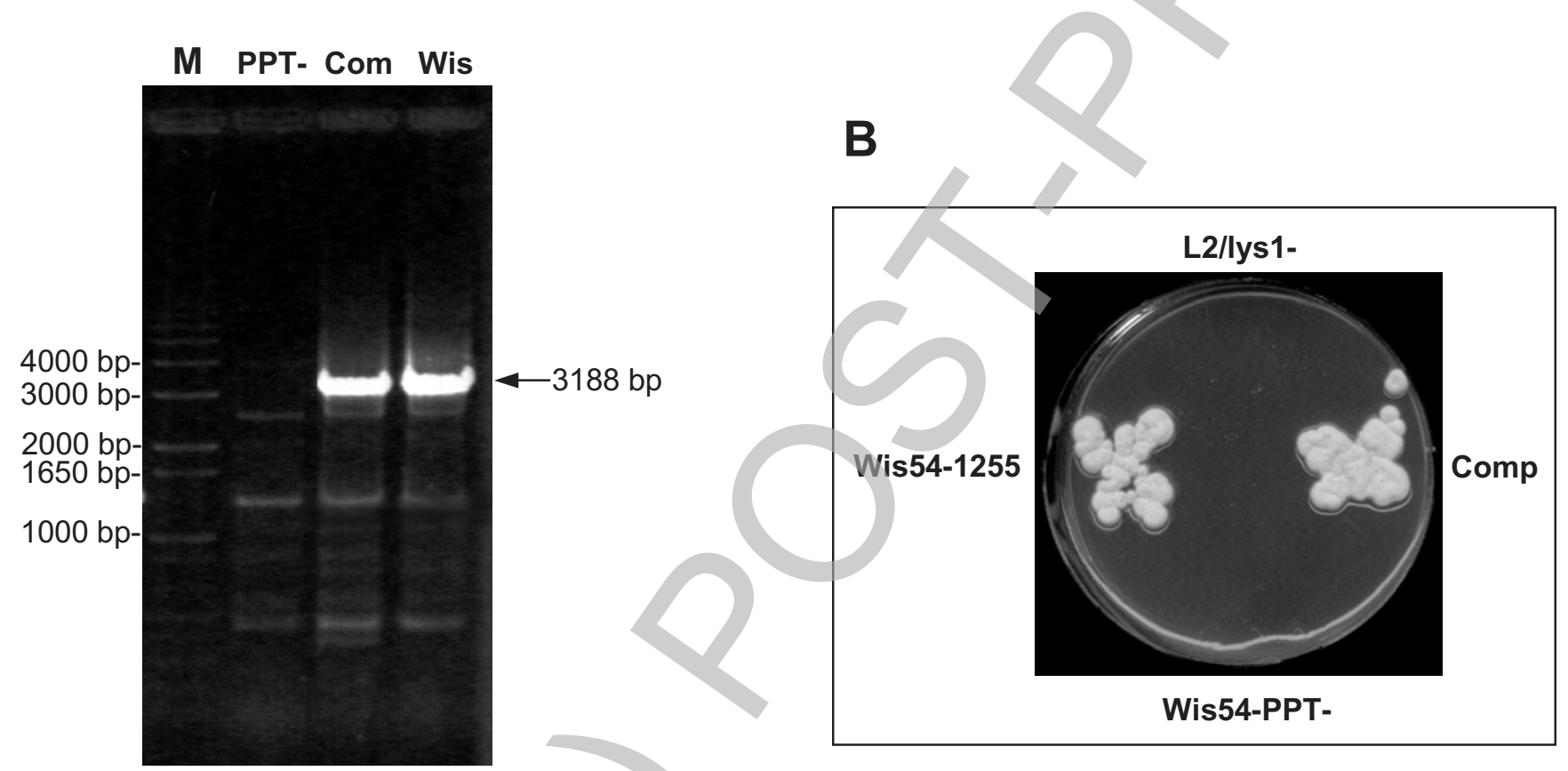

Figure 6. García-Estrada et al.

Licenced copy. Copying is not permitted, except with prior permission and as allowed by law.

(C) 2008 The Authors Journal compilation (C) 2008 Biochemical Society 